\title{
Randomized Controlled Trial for Helicobacter pylori Eradication in a Naive Portuguese Population: Is Sequential Treatment Superior to Triple Therapy in Real World Clinical Setting?
}

\author{
Ensaio Clínico Randomizado para o Tratamento do \\ Helicobacter pylori em Doentes Portugueses Naive: É o \\ Tratamento Sequencial Superior ao Tratamento Triplo na \\ Prática Clínica?
}

Pedro BOAL CARVALHO $\triangle^{1}$, Joana MAGALHÃES ${ }^{1}$, Francisca DIAS DE CASTRO ${ }^{1}$, Bruno ROSA ${ }^{1}$, José COTTER ${ }^{1,2,3}$ Acta Med Port 2017 Mar;30(3):185-189 - https://doi.org/10.20344/amp.8072

\begin{abstract}
Introduction: Helicobacter pylori eradication has become increasingly difficult as resistances to several antibiotics develop. We aimed to compare Helicobacter pylori eradication rates between triple therapy and sequential therapy in a naive Portuguese population.

Material and Methods: Prospective randomized trial including consecutive patients referred for first-line Helicobacter pylori eradication treatment. Exclusion criteria: previous gastric surgery/neoplasia, pregnancy/lactancy, allergy to any of the drugs. The compared eradication regimens were triple therapy (pantoprazol, amoxicillin and clarithromycin 12/12 hours, 14 days) and sequential therapy (pantoprazol 12/12 hours for 10 days, amoxicillin 12/12 hours for days 1 - 5 and clarithromycin plus metronidazol 12/12 hours during days 6 - 10). Eradication success was confirmed with urea breath test. Statistical analysis was performed with SPSS v21.0 and a $p$-value $<0.05$ was considered statistically significant.

Results: Included 60 patients, $39(65 \%)$ female with mean age 52 years (SD \pm 14.3 ). Treatment groups were homogeneous for gender, age, indication for treatment and smoking status. No statistical differences were encountered between sequential and triple therapy eradication rates $(86.2 \%$ vs $77.4 \%, p=0.379)$, global eradication rate was $82 \%$. Tobacco consumption was associated with a significantly lower eradication success $(54.5$ vs $87.8 \%, p=0.022)$.

Discussion: In this randomized controlled trial in a naive Portuguese population, we found a satisfactory global Helicobacter pylori eradication rate of $82 \%$, with no statistical differences observed in the efficacy of the treatment between triple and sequential regimens. Conclusion: These results support the use of either therapy for the first-line eradication of Helicobacter pylori.

Keywords: Anti-Bacterial Agents; Drug Therapy, Combination; Helicobacter Infections/drug therapy; Helicobacter pylori; Portugal; Stomach Neoplasms
\end{abstract}

\section{RESUMO}

Introdução: A erradicação do Helicobacter pylori tem adquirido dificuldade progressiva, devido às resistências para os antibióticos utilizados. Pretendemos comparar a eficácia na erradicação do Helicobacter pylori entre o tratamento triplo e sequencial numa população portuguesa naive.

Material e Métodos: Trabalho prospectivo randomizado incluindo doentes consecutivos submetidos a primeiro tratamento de erradicação do Helicobacter pylori. Critérios de exclusão: cirurgia/neoplasia gástrica prévias, gravidez/aleitamento, alergia a algum dos fármacos. Os esquemas utilizados foram o tratamento triplo (pantoprazol, amoxicilina claritromicina 12/12 horas, 14 dias) e tratamento sequencial (pantoprazol 12/12 horas durante 10 dias, amoxicilina 12/12 horas nos dias 1 - 5 e claritromicina e metronidazol 12/12 horas nos dias 6 - 10). A eficácia da erradicação foi confirmada com um teste respiratório da ureia. A análise estatística foi efectuada com o SPSS v21.0 e um valor de $p<0,05$ foi considerado estatisticamente significativo.

Resultados: Incluídos 60 doentes, 39 (65\%) mulheres, idade média 52 anos (DP \pm 14,3). Os grupos de tratamento foram homogéneos para as variáveis sexo, idade, indicação para tratamento e tabagismo. Não foram observadas diferenças estatisticamente significativas na eficácia de erradicação do Helicobacter pylori entre o tratamento triplo e sequencial $(86,2 \%$ vs $77,4 \%, p=0,379)$, com uma taxa global de erradicação de $82 \%$. O tabagismo foi associado significativamente a uma menor eficácia de erradicação (54,5 vs $87,8 \%$, $p=0,022$ ).

Discussão: Neste ensaio clínico randomizado numa população portuguesa naive, encontrámos uma eficácia global de erradicacão do Helicobacter pylori de $82 \%$, sem diferenças estatisticamente significativas entre o tratamento triplo e o tratamento sequencial.

Conclusão: Estes resultados reforçam a possibilidade de utilizar qualquer um destes tratamentos como primeira linha na erradicação do Helicobacter pylori.

Palavras-chave: Farmacoterapia Combinada; Helicobacter pylori; Infecções por Helicobacter/tratamento; Neoplasias do Estômago; Portugal

\footnotetext{
1. Serviço de Gastrenterologia. Hospital da Senhora da Oliveira. Guimarães. Portugal.

2. Life and Health Sciences Research Institute. School of Health Sciences. Universidade do Minho. Braga. Portugal.

3. ICVS/3B's. PT Government Associate Laboratory. Guimarães/Braga. Portugal.

$\square$ Autor correspondente: Pedro Boal Carvalho. pedroboalcarvalho@chaa.min-saude.pt

Recebido: 26 de julho de 2016 - Aceite: 23 de novembro de 2016 | Copyright @ Ordem dos Médicos 2017
} 


\section{INTRODUCTION}

Helicobacter pylori (HP) is the most prevalent human infectious pathogen, ${ }^{1}$ affecting more than $50 \%$ of the world adult population. ${ }^{1}$ The prevalence of HP infection varies widely across populations, ${ }^{2}$ depending on geographical and demographic factors - in Northern Europe the prevalence is reported to be below $40 \%,{ }^{2}$ in Japan $70 \%,{ }^{2}$ and in Portugal the prevalence of HP was $90 \%$ two decades ago, ${ }^{3}$ and $84 \%$ in a recent study by Bastos et al. ${ }^{4}$

$\mathrm{HP}$ is a known carcinogenic agent to humans, ${ }^{5}$ responsible for 660000 cases of cancer worldwide ${ }^{6}$ - more than $75 \%$ of all gastric cancers, ${ }^{6}$ half of the infection-associated cancers in developed countries. ${ }^{6} \mathrm{HP}$ is also associated with gastrointestinal non-malignant diseases, such as functional dyspepsia, ${ }^{7}$ gastritis and peptic ulcer disease,${ }^{8}$ as well as with iron-deficient anemia, ${ }^{9}$ idiopathic thrombocytopenic purpura ${ }^{10}$ and risk of cardiovascular events. ${ }^{11}$ In fact, it has been demonstrated that HP eradication not only improves most non-malignant associated diseases, but may also reduce the future risk of gastric cancer by up to $80 \%,{ }^{12}$ and a recent meta-analysis suggests that population screening and eradication of HP strategy is cost-effective. ${ }^{13}$

According to the Maastricht IV Consensus on HP management, ${ }^{1}$ clarithromycin resistance in each region should determine the most adequate first-line treatment for HP eradication - in regions where the clarithromycin resistance is inferior to $15 \%-20 \%$, the triple therapy (TT), containing a proton-pump inhibitor (PPI), amoxicillin and clarithromycin, is adequate, whereas if the resistance to clarithromycin is superior to this threshold, other treatment options, such as the sequential treatment (ST) (PPI plus amoxicillin followed by PPI, clarithromycin and an imidazole) could be preferable.

In Europe, an increase in clarithromycin resistance from 10 to $17.5 \%^{14}$ has been witnessed in the last decade, and the latest data from central Portugal indicates a resistance rate of $21.4 \% .^{15}$

A meta-analysis by Gatta et al, ${ }^{16}$ comparing 14-day TT versus ST, found no differences in HP eradication rate, but prospective Western European studies comparing both strategies are currently lacking, and the most adequate first-line eradication regimen for HP in Portugal has not yet been determined.

We aimed to compare HP eradication rates between 14day TT and 10-day ST in a naive Portuguese population, as well as to analyse other factors associated with a reduced treatment efficacy.

\section{MATERIAL AND METHODS}

We performed a prospective, unicentric, open-label randomized trial in the Gastroenterology department of our institution.

Inclusion criteria included outpatients with over 18 years with newly diagnosed HP infection. The diagnosis of HP infection was performed by immunohistochemical staining in gastric biopsy specimens performed during a recent esophagogastroduodenoscopy ( $\leq 6$ months). The enrollment period was 12 months.

Patients were excluded if they had been previously treated for HP, had a previous gastric surgery or gastric cancer, were diagnosed with severe medical illnesses, such as liver failure or heart failure, were treated with antibiotics in the four weeks before enrollment or between the diagnosis and enrollment, had a known allergy to any of the treatment drugs, or were pregnant or lactating women.

Patients' demographic variables (gender, age), comorbidities, current medication, indication for eradication and smoking status were registered.

Sample size was calculated, based on both previous Portuguese ${ }^{15}$ and European studies, ${ }^{1}$ for a $95 \%$ confidence interval and power of 0.8 , to be $n=59$.

Randomization was performed in blocks of 10 , using opaque envelopes kept by an independent researcher, and distributed to the investigators after an informed consent for study investigation was given by the patients.

Patients were randomized to either TT (pantoprazol 40 $\mathrm{mg}$, amoxicillin $1000 \mathrm{mg}$ and clarithromycin $500 \mathrm{mg} \mathrm{12/12}$ hours for 14 days) and ST (pantoprazol $40 \mathrm{mg} 12 / 12$ hours for 10 days, amoxicillin $1000 \mathrm{mg} \mathrm{12/12}$ hours during days $1-5$ and clarithromycin $500 \mathrm{mg} \mathrm{12/12} \mathrm{hours,} \mathrm{metronidazol}$

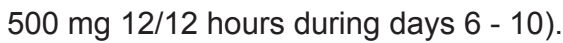

Drug compliance was confirmed through self-report by direct patient questioning, and noncompliance was defined as failure to take at least $80 \%$ of the prescribed treatment regimen. Side-effects of medication were recorded, as well as the need to discontinue treatment for major side-effects or allergies.

Eradication success was assessed by a laboratorial technician blinded to the treatment allocation, through ${ }^{13} \mathrm{C}$-Urea Breath Test $\left({ }^{13} \mathrm{C}\right.$-UBT $)$, performed $4-6$ weeks after treatment termination, and PPI suspension was mandatory for the two weeks previous to the test.

Per protocol (PP) and modified intention to treat analysis (MITT) - patients receiving at least one dose of treatment and with an available ${ }^{13} \mathrm{C}$-UBT result - was performed.

Secondary analysis of incidence of side-effects, treatment discontinuation, drug compliance and individual factors associated with decreased eradication success was performed.

Statistical analysis was performed using SPSS $21.1^{\mathrm{TM}}$ (WinWrap Basics ${ }^{\mathrm{TM}}$ ), through univariate analysis, using independent-samples $t$ test for continuous variables and the chi-square test for categorical variables. Statistical significance was defined for $p$-value $<0.05$, and quantitative variables were presented as mean \pm standard deviation (SD).

This study was conducted in accordance with the principles of the Declaration of Helsinki, ICH Guidelines for Good Clinical Practice and in full conformity with relevant regulations. Patients provided written informed consent for study participation. The study protocol was approved by the local ethics committee. 
Table 1 - Patients' sociodemographic characteristics

\begin{tabular}{|c|c|c|c|c|}
\hline & $\begin{array}{l}\text { All patients } \\
(n=60)\end{array}$ & $\begin{array}{l}\text { TT group } \\
(\mathrm{n}=31)\end{array}$ & $\begin{array}{l}\text { ST group } \\
(n=29)\end{array}$ & $p$ \\
\hline Female (\%) & 65.0 & 64.5 & 65.5 & 0.935 \\
\hline Age, years $($ mean $\pm S D)$ & $53 \pm 14$ & $49.8 \pm 14.3$ & $48.1 \pm 13.7$ & 0.868 \\
\hline $\begin{array}{l}\text { Smoking status } \\
\text { Smokers (\%) } \\
\text { Non-smokers (\%) }\end{array}$ & $\begin{array}{l}18.3 \\
81.7\end{array}$ & $\begin{array}{l}13.8 \\
86.2\end{array}$ & $\begin{array}{l}22.6 \\
77.4\end{array}$ & 0.379 \\
\hline $\begin{array}{l}\text { Indication for eradication } \\
\text { Functional dyspepsia (\%) } \\
\text { Peptic ulcer disease (\%) } \\
\text { Pre-malignant gastric lesions (\%) } \\
\text { Other (\%) }\end{array}$ & $\begin{array}{l}41.7 \\
13.3 \\
23.3 \\
21.7\end{array}$ & $\begin{array}{l}41.9 \\
12.9 \\
29.0 \\
16.2\end{array}$ & $\begin{array}{l}41.4 \\
13.8 \\
17.2 \\
27.8\end{array}$ & 0.714 \\
\hline
\end{tabular}

TT: Triple therapy; ST: Sequential therapy

\section{RESULTS}

From January to December 2014, 63 patients fulfilled the inclusion criteria and were randomized (32 to TT, 31 to ST); three patients were lost to follow-up and failed to return to ${ }^{13} \mathrm{C}-\mathrm{UBT}$, and were excluded from the MITT and PP analysis. No patient refused to participate, and no allergies were documented during the study, resulting in 31 patients in the TT group and 29 patients in the ST group.

Of the remaining 60 patients, $39(65 \%)$ were female with mean age 52 years (SD \pm 14.3$)$. Chief indications for HP eradication were functional dyspepsia (41.7\%), premalignant gastric lesions - extensive atrophic gastritis or intestinal metaplasia, low grade dysplasia - $(23.3 \%)$ and peptic ulcer disease (13.3\%), while unexplained irondeficient anemia was the indication in $10.0 \%$ of the cases, familial history of gastric cancer in $6.7 \%$ and hyperplastic polyps in $5.0 \%$ of the patients. Smoking status was positive for $18.3 \%$ of the patients, while $81.7 \%$ were non-smokers. Clinical characteristics of all patients, TT group and ST group are summarized on Table 1. TT and ST groups were homogeneous for gender, age, indication for treatment, and smoking status.

No statistical differences were encountered between ST and TT either on PP $(85.2 \%$ vs $76.7 \%, p=0.416)$ or MITT (86.2\% vs $77.4 \%, p=0.379)$ analysis, global eradication rate was $80.7 \%$ in the PP and 81.7 in the MITT analysis.

Side-effects were reported in $12(20.0 \%)$ patients (six in each treatment arm), most commonly dyspepsia, diarrhea and dysgeusia - Table 2. Only three patients (5.0\%) were non-compliant, two on the ST group and one on the TT

Table 2 - Side-effects of medication

\begin{tabular}{lcc}
\hline & $\begin{array}{c}\text { TT group } \\
(\mathbf{n}=\mathbf{3 1 )}\end{array}$ & $\begin{array}{c}\text { ST group } \\
(\mathbf{n}=\mathbf{2 9})\end{array}$ \\
\hline Any, n (\%) & $6(19.3)$ & $6(20.7)$ \\
Dyspepsia, n (\%) & $2(6.4)$ & $4(13.7)$ \\
Nausea / vomiting, n (\%) & $1(3.2)$ & $0(0)$ \\
Diarrhea, n (\%) & $3(9.6)$ & $2(6.8)$ \\
Dysgeusia, $\mathrm{n}(\%)$ & $0(0)$ & $1(3.4)$ \\
\hline
\end{tabular}

TT: Triple therapy; ST: Sequential therapy group; in one patient in the TT group the treatment was interrupted after 11 days for nausea and vomiting, and in two patients in the ST group, noncompliance resulted from complaints of diarrhea and dyspepsia, respectively remarkably, eradication was successful in the three patients.

Patient demographic factors, smoking status, indications for treatment and treatment compliance were analyzed to assess their impact on treatment outcome. Positive smoking status was associated with a significantly lower eradication success (54.5 vs $87.8 \%, p=0.022$ ); age, gender, indication for treatment and compliance status were not associated with an impact on treatment success.

\section{DISCUSSION}

The worldwide health burden of HP is a consequence of its high prevalence ${ }^{1,2,4}$ together with a significant number of associated diseases, mainly gastric adenocarcinoma, MALT lymphoma ${ }^{6}$ and peptic ulcer disease. ${ }^{8}$

In the last decades, a decreasing trend in prevalence of HP across the world was observed, declining to $20 \%-40 \%$ in the United States of America ${ }^{17}$ and less than $30 \%$ in some European countries. ${ }^{2}$ Nevertheless, in Southern Europe the prevalence of HP is still high, and in Portugal no decrease was observed in the past 20 years, ${ }^{3,18}$ currently $84 \%{ }^{4}$ and resulting in one of the highest gastric cancer mortality rates in Europe. ${ }^{18}$

In 2012, the Maastricht IV Report consensus considered the standard TT to be an adequate first-line treatment for regions where clarithromycin resistance rates were inferior to $15 \%-20 \%,{ }^{1}$ but should be abandoned in favor of other regimens in regions of higher resistance prevalence. The rate of clarithromycin resistance in Portugal has most recently been shown to be $21.4 \%{ }^{15}$ in study including patients from central Portugal, but significant variability within the country has been observed, ranging from $14.6 \%$ to $33 \%{ }^{14,19,20}$

In our work, the global HP eradication rate in Portuguese naive patients from a Northern region was over $80 \%$, and no significant differences in efficacy were observed between 14-day TT and 10-day ST, either on PP $(85.2 \%$ vs $76.7 \%$, $p=0.416)$ or MITT $(86.2 \%$ vs $77.4 \%, p=0.379)$ analysis.

These results are comparable to the ones reported 
by two recent multicentre trials involving naive patients: a Taiwanese trial by Liou et al, ${ }^{21}$ observed no significant differences between 10-day ST (87.0\%) and 14-day TT (82.3\%) eradication rates, and Greenberg et $a^{22}$ conducted a multicentre study including several countries in South America, reporting no advantages in the eradication rate when using ST (76.5\%) compared to 14-day TT (82.6\%) crucially, a study developed in countries with clarithromycin resistance rates superior to $20 \% .^{23}$

In a meta-analysis from Gatta et al, ${ }^{16}$ ST was superior to 7-day and 10-day TT, but no advantage of ST was observed if TT was prolonged for 14 days (eradication rates $80.8 \%$ vs $81.3 \%$, respectively), reflecting an improvement between $5.0 \%$ and $9.8 \%{ }^{1,16}$ in TT eradication rates with a 14-day course, and these results were replicated subsequently in another meta-analysis by Feng et al. ${ }^{24}$ Prospective Western European studies directly comparing 14-day TT with 10-day ST are currently lacking.

In Portugal, Cerqueira et $a^{20}$ reported 14-day TT eradication rates of $58.6 \%$ (ITT) and $62.9 \%$ (PP) in obese patients undergoing bypass surgery, and Almeida et $a /^{15}$ observed eradication rates of $68.9 \%$ (ITT) and $68.8 \%$ (PP) with the same regimen in a population-based study. These contrasting results, reflecting a wide variation in eradication rates in the same country, probably reflect clarithromycin resistance variability across different regional populations. ${ }^{14,15,19}$

Newer treatment options, such as concomitant ${ }^{25,26}$ (TT plus metronidazole), hybrid ${ }^{27,28}$ (ST, but with amoxicillin added during the second half of the regimen) and dual ${ }^{29}$ (high dose PPI plus amoxicillin, four doses daily) treatment have been developed, in order to achieve eradication rates $>90 \%$, as defended by Graham et al, ${ }^{30}$ and have shown superior eradication rates compared to TT, but in most of them, TT duration was inferior to 14 days..$^{26,27,29}$ Regarding ST, a recent meta-analysis comparing it with hybrid and concomitant therapies showed no efficacy advantage in the newer treatment strategies. ${ }^{31}$ Bismuth-based regimens, advocated in the Maastricht IV Consensus as a firstline treatment option in regions with high clarithromycin resistance, ${ }^{1}$ has shown favorable results, ${ }^{32}$ but bismuth is not widely available in many European countries, in particular in Portugal. Levofloxacin-based treatments have shown increasingly worse results in the last few years, and a meta-analysis failed so show superiority versus both TT $(80.2 \%$ vs $77.4 \%, 95 \% \mathrm{Cl}=0.94-1.13),{ }^{33}$ probably due to the increasing prevalence of levofloxacin-resistant strains of HP in many European countries. ${ }^{14,15}$

Importantly, both bismuth-based therapies and the newer treatment regimens (hybrid, concomitant and dual), are often complex and exhausting, leading to potentially lower drug compliance as well as to an increased risks of side-effects or overdosing outside clinical trials. ${ }^{34,35}$ In a recent multicentre study, ${ }^{27}$ patients on hybrid or concomitant treatment reported significantly more side-effects than those on TT (81 and $79 \%$ vs $27 \%, p=0.012$ ), while Delchier et $a^{\beta 6}$ observed side-effects in $67 \%$ of the patients treated with bismuth.

In our work, side-effects were reported by $20 \%$ of our patients, predominantly dyspepsia, diarrhea and dysgeusia with no differences between TT (19.3\%) and ST (20.7\%). Both the incidence and type of reported side-effects are consistent with the ones reported in the literature for these treatment strategies, ${ }^{27,31}$ as well as the non-compliance rate of $5 \%{ }^{26,27}$

Finally, tobacco consumption was significantly associated with and lower rates of HP eradication (54.5 vs $87.8 \%, p=0.022)$. The effect of active smoking in the efficacy of HP eradication has been previously reported in a meta-analysis (odds-ratio for treatment failure among smokers versus non-smokers was $1.95(95 \% \mathrm{Cl}$ : $1.55-$ 2.45; $p<0.01),{ }^{37}$ and on a recent prospective study in a Portuguese population ${ }^{15}$ - suggested explanations for this occurrence include a reduction of antibiotic delivery due to a decreased gastric blood flow, a decrease in intra-gastric $\mathrm{pH}$ in smokers, a potentially adjuvant mechanism of nicotine to the vacuolating toxin activity of HP, as well as smoking being generally associated with poorer compliance. ${ }^{1}$

Our study has some limitations: it reports to a small sample size, resulting from strict inclusion criteria in a prospective, randomized trial; it was an open label study, but the risk of bias associated with this methodology was very low, as the outcome assessment $\left({ }^{13} \mathrm{C}\right.$-UBT) was performed by a technician blinded to the treatment strategy. Finally, we performed no antibiotic resistance profiling. Although resistances to clarithromycin, metronidazol, or even to both, are on the rise, significant heterogeneity across countries and regions may result in unpredictable eradication rates when using standard treatments. ${ }^{14}$ Antibiotic resistance profiling could result in a tailored approach to HP treatment and superior primary eradication rates, but at the cost of delays in treatment and increased risk of loss to follow-up.

\section{CONCLUSION}

In conclusion, we report for the first time the results from a randomized controlled trial for HP eradication in naive Portuguese patients comparing two recommended regimens by the Maastricht IV Consensus ${ }^{1}$, finding no statistically significant differences between 14-day TT and 10-day ST. Despite the need for larger prospective studies to confirm the most adequate treatment strategy for HP in a Southern European country, our results support the use of either TT or ST for the first-line eradication of Helicobacter pylori.

\section{PROTECTION OF HUMANS AND ANIMALS}

This study was conducted in accordance with the principles of the Declaration of Helsinki, ICH Guidelines for Good Clinical Practice and in full conformity with relevant regulations. Patients provided written informed consent for study participation. The study protocol was approved by the local ethics committee. 


\section{DATA CONFIDENTIALITY}

The authors declare having followed the protocols in use at their working center regarding patients' data publication.

\section{CONFLICTS OF INTEREST}

All authors report no conflict of interest.

\section{REFERENCES}

1. Malfertheiner P, Megraud F, O'Morain CA, Atherton J, Axon AT, Bazzoli $\mathrm{F}$, et al. Management of helicobacter pylori infection - the Maastricht IV/ Florence Consensus Report. Gut. 2012;61:646-64.

2. Peleteiro B, Bastos A, Ferro A, Lunet N. Prevalence of helicobacter pylori infection worldwide: a systematic review of studies with national coverage. Dig Dis Sci. 2014;59:1698-709.

3. Quina MG. Helicobacter pylori: the Portuguese scene. Grupo de Estudo Português do Helicobacter pylori (GEPHP). Eur J Cancer Prev. 1994;3:S65-7.

4. Bastos J, Peleteiro B, Barros R, Alves L, Severo M, de Fatima Pina $M$, et al. Sociodemographic determinants of prevalence and incidence of Helicobacter pylori infection in Portuguese adults. Helicobacter. 2013;18:413-22.

5. Bouvard V, Baan R, Straif K, Grosse Y, Secretan B, El Ghissassi F, et al. A review of human carcinogens-Part B: biological agents. Lancet Oncol. 2009;10:321-2.

6. de Martel C, Ferlay J, Franceschi S, Vignat J, Bray F, Forman D, et al. Global burden of cancers attributable to infections in 2008: a review and synthetic analysis. Lancet Oncol. 2012;13:607-15.

7. Moayyedi P, Deeks J, Talley NJ, Delaney B, Forman D. An update of the Cochrane systematic review of helicobacter pylori eradication therapy in nonulcer dyspepsia: resolving the discrepancy between systematic reviews. Am J Gastroenterol. 2003;98:2621-6.

8. Leodolter A, Kulig M, Brasch $H$, Meyer-Sabellek W, Willich SN, Malfertheiner P. A meta-analysis comparing eradication, healing and relapse rates in patients with Helicobacter pylori-associated gastric or duodenal ulcer. Aliment Pharmacol Ther. 2001;15:1949-58.

9. Franceschi F, Gasbarrini A, Polyzos SA, Kountouras J. Extragastric diseases and helicobacter pylori. Helicobacter. 2015;20:S40-6.

10. Brito HS, Braga JA, Loggetto SR, Machado RS, Granato CF, Kawakami E. Helicobacter pylori infection \& immune thrombocytopenic purpura in children and adolescents: a randomized controlled trial. Platelets. 2015;26:336-41.

11. Liu J, Wang F, Shi S. Helicobacter pylori Infection Increase the risk of myocardial infarction: a meta-analysis of 26 studies involving more than 20,000 participants. Helicobacter. 2015;20:176-83.

12. Venerito M, Vasapolli R, Rokkas T, Malfertheiner P. Helicobacter pylori and gastrointestinal malignancies. Helicobacter. 2015;20:S36-9.

13. Areia M, Carvalho R, Cadime AT, Rocha Goncalves F, Dinis-Ribeiro M. Screening for gastric cancer and surveillance of premalignant lesions: a systematic review of cost-effectiveness studies. Helicobacter. 2013;18:325-37

14. Megraud F, Coenen S, Versporten A, Kist M, Lopez-Brea M, Hirschl AM, et al. Helicobacter pylori resistance to antibiotics in Europe and its relationship to antibiotic consumption. Gut. 2013;62:34-42.

15. Almeida N, Donato MM, Romaozinho JM, Luxo C, Cardoso O, Cipriano MA, et al. Beyond Maastricht IV: are standard empiric triple therapies for helicobacter pylori still useful in a South-European country? BMC Gastroenterol. 2015;15:23.

16. Gatta L, Vakil N, Vaira D, Scarpignato C. Global eradication rates for Helicobacter pylori infection: systematic review and meta-analysis of sequential therapy. BMJ. 2013;347:f4587.

17. Ferlay J, Soerjomataram I, Dikshit R, Eser S, Mathers C, Rebelo M, et al. Cancer incidence and mortality worldwide: sources, methods and major patterns in GLOBOCAN 2012. Int J Cancer. 2015;136:E359-86.

18. Morais S, Ferro A, Bastos A, Castro C, Lunet N, Peleteiro B. Trends in gastric cancer mortality and in the prevalence of helicobacter pylori infection in Portugal. Eur J Cancer Prev. 2016l;25:275-81.

19. Cabrita J, Oleastro M, Matos R, Manhente A, Cabral J, Barros R, et al. Features and trends in Helicobacter pylori antibiotic resistance in Lisbon area, Portugal (1990-1999). J Antimicrob Chemother. 2000;46:1029-31.

\section{FUNDING SOURCES}

No funding or grant was received for this manuscript.

20. Cerqueira RM, Correia MR, Fernandes CD, Vilar H, Manso MC Cumulative helicobacter pylori eradication therapy in obese patients undergoing gastric bypass surgery. Obes Surg. 2013;23:145-9.

21. Liou JM, Chen CC, Chen MJ, Chen CC, Chang CY, Fang YJ, et al. Sequential versus triple therapy for the first-line treatment of Helicobacter pylori: a multicentre, open-label, randomised trial. Lancet. 2013;381:205-13.

22. Greenberg ER, Anderson GL, Morgan DR, Torres J, Chey WD, Bravo LE, et al. 14-day triple, 5-day concomitant, and 10-day sequential therapies for Helicobacter pylori infection in seven Latin American sites: a randomised trial. Lancet. 2011;378:507-14.

23. De Francesco V, Giorgio F, Hassan C, Manes G, Vannella L, Panella C, et al. Worldwide H. pylori antibiotic resistance: a systematic review. J Gastrointestin Liver Dis. 2010;19:409-14.

24. Feng L, Wen MY, Zhu YJ, Men RT, Yang L. Sequential therapy or standard triple therapy for helicobacter pylori infection: an updated systematic review. Am J Ther. 2016;23:e880-93.

25. Molina-Infante J, Lucendo AJ, Angueira T, Rodriguez-Tellez M, PerezAisa A, Balboa A, et al. Optimised empiric triple and concomitant therapy for helicobacter pylori eradication in clinical practice: the OPTRICON study. Aliment Pharmacol Ther. 2015;41:581-9.

26. Ang TL, Fock KM, Song M, Ang D, Kwek AB, Ong J, et al. Ten-day triple therapy versus sequential therapy versus concomitant therapy as firstline treatment for helicobacter pylori infection. J Gastroenterol Hepatol. 2015;30:1134-9.

27. Cuadrado-Lavin A, Salcines-Caviedes JR, Diaz-Perez A, Carrascosa MF, Ochagavia M, Fernandez-Forcelledo JL, et al. First-line eradication rates comparing two shortened non-bismuth quadruple regimens against helicobacter pylori: an open-label, randomized, multicentre clinical trial. J Antimicrob Chemother. 2015;70:2376-81.

28. Hsu PI, Wu DC, Wu JY, Graham DY. Modified sequential helicobacter pylori therapy: proton pump inhibitor and amoxicillin for 14 days with clarithromycin and metronidazole added as a quadruple (hybrid) therapy for the final 7 days. Helicobacter. 2011;16:139-45.

29. Yang JC, Lin CJ, Wang HL, Chen JD, Kao JY, Shun CT, et al. Highdose dual therapy is superior to standard first-line or rescue therapy for helicobacter pylori infection. Clin Gastroenterol Hepatol. 2015;13:895905.e5.

30. Graham DY, Lu H, Yamaoka Y. A report card to grade Helicobacter pylori therapy. Helicobacter. 2007;12:275-8.

31. Wang $B$, Wang $Y H$, Lv ZF, Xiong HF, Wang $H$, Yang $Y$, et al. Review: efficacy and safety of hybrid therapy for Helicobacter pylori infection: a systematic review and meta-analysis. Helicobacter. 2015;20:79-88.

32. O'Connor A, Gisbert JP, O'Morain C, Ladas S. Treatment of helicobacter pylori infection 2015. Helicobacter. 2015;20:S54-61.

33. Xiao SP, Gu M, Zhang GX. Is levofloxacin-based triple therapy an alternative for first-line eradication of Helicobacter pylori? A systematic review and meta-analysis. Scand J Gastroenterol. 2014;49:528-38.

34. Essa AS, Kramer JR, Graham DY, Treiber G. Meta-analysis: fourdrug, three-antibiotic, non-bismuth-containing "concomitant therapy" versus triple therapy for Helicobacter pylori eradication. Helicobacter. 2009;14:109-18.

35. Heo J, Jeon SW. Optimal treatment strategy for Helicobacter pylori: era of antibiotic resistance. World J Gastroenterol. 2014;20:5654-9.

36. Delchier JC, Malfertheiner P, Thieroff-Ekerdt R. Use of a combination formulation of bismuth, metronidazole and tetracycline with omeprazole as a rescue therapy for eradication of helicobacter pylori. Aliment Pharmacol Ther. 2014;40:171-7.

37. Suzuki T, Matsuo K, Ito H, Sawaki A, Hirose K, Wakai K, et al. Smoking increases the treatment failure for helicobacter pylori eradication. Am J Med. 2006;119:217-24. 